\title{
Effect of Acetamınophen on Ovulation and Implantation in Female Mice
}

\author{
Ndeke $\mathrm{AN}^{1,3}$, Mutembei $\mathrm{HM}^{1}$, Kaingu $\mathrm{CK}^{2}$ and Muthee $\mathrm{JK}^{1}$ \\ ${ }^{1}$ Clinical studies Department, Faulty of Veterinary Medicine University of Nairobi, Kenya \\ ${ }^{2}$ Department of Veterinary Anatomy and Physiology, Faculty of Veterinary Medicine, University of Nairobi, Kenya \\ ${ }^{3}$ The Andys Veterinary Clinic, Loresho Branch, Nairobi, Kenya \\ *Corresponding author: annendeke@uonbi.ac.ke
}

\begin{tabular}{|c|c|c|}
\hline Article History: 20-162 & Received: 20-Jul-20 & Accepted: $31-$ Oct-20 \\
\hline \multicolumn{3}{|l|}{ ABSTRACT } \\
\hline $\begin{array}{l}\text { Acetaminophen is known } \\
\text { linked to the regulation } \\
\text { acetaminophen reproduct } \\
\text { study was designed to de } \\
\text { mice were randomly divi } \\
\text { implantation. The two grc } \\
\text { mice in the treatment gro } \\
\text { (CG1 and CG2) received } \\
\text { acetaminophen/placebo b } \\
\text { for seven days post-matin } \\
7^{\text {th day of pregnancy, the }} \\
\text { groups (TG1 and TG2), } \\
\text { compared with the respec } \\
\text { in the regulation of ovulat }\end{array}$ & $\begin{array}{l}\text { inhibit prostaglandin synthesis and activate the endo } \\
\text { mammalian reproductive processes through the san } \\
\text { effects in the regulation of ovulation and/or implanta } \\
\text { mine the effect of acetaminophen on ovulation and/ } \\
\text { into two experiments, one testing effects on ovula } \\
\text { s were further sub-divided into treatment and contro } \\
\text { (TG1 and TG2) received } 200 \mathrm{mg} / \mathrm{kg} \text { of acetaminoph } \\
\text { rame quantities of normal saline. Mice in experim } \\
\text { re mating. Those in experiment group two (TG } 2 \text {, C } \\
\text { rhe presence of a vaginal plug confirmed mating suc } \\
\text { ignificant reduction in the number of implantation } \\
\text { e control group (CG1 and CG2). The observation po } \\
\text { and implantation in female mice reproduction. }\end{array}$ & $\begin{array}{l}\text { oid system, thereby has been } \\
\text { wing evidence tends to link } \\
\text { rovide further evidence, this } \\
\text { ntation. Female Swiss white } \\
\text { the other testing effects on } \\
\text { each having } \mathrm{N}=5 \text { mice. The } \\
\text { those in the control groups } \\
\text { tp one (TG1, CG1) received } \\
\text { ived acetaminophen/placebo } \\
\text { mice were sacrificed on the } \\
\text { recorded. In both treatment } \\
\leq 0.05 \text { ) was observed when } \\
\text { ards a role of acetaminophen }\end{array}$ \\
\hline
\end{tabular}

Key words: Acetaminophen, Ovulation, Implantation, Mice, Reproduction.

(02020 IJVS - All Rights Reserved

\section{INTRODUCTION}

The Endocannabinoid System (ECS) has been shown to play a role in the regulation of mammalian reproductive processes through the synchronous crosstalk between the endometrium and the embryo to guarantee timely and successful implantation (Correa et al. 2016). Endocannabinoids that serve as ECS ligands are known to work through cannabinoid receptor type 1 (CB1) and 2 (CB2) and related enzymes, which have been demonstrated to be present in females (Cui et al. 2017; Cecconi et al. 2020).

Acetaminophen has been demonstrated to undergo metabolic deacetylation in the liver to yield $p$-aminophenol (Mazaleuskaya et al. 2015) that undergo further conjugation with arachidonic acid via fatty acid amide hydrolase (FAAH) to result in the formation of $\mathrm{N}$ arachidonoyl-phenolamine (AM404) in the central nervous system (Sharma et al. 2017). It is the AM404 that activates the endocannabinoid system by selectively binding to the cannabinoid receptor type 1 (CB1) to inhibit cellular uptake of anandamide. The inhibition of cellular uptake of anandamide leads to increased build-up in levels of the same (anandamide) within the extracellular space to regulate female reproductive processes probably at the levels of ovulation and/or implantation (Cui et al. 2017; Walker et al. 2019). This experiment was carried out to provide further clarification on the probable role of acetaminophen in the regulation of female reproduction using the mice as a model.

\section{MATERIALS AND METHODS}

All experimental procedures and ethical considerations on the use of animals were carried out as guided by the Kenyan animal welfare guidelines and approvals obtained from the Faculty of Veterinary Medicine University of Nairobi Biosafety, Animal Use, and Ethics committee - (FVM BAUEC/2019/187).

Female, Swiss white mice aged between 8-10 weeks old and weighing between $20-35 \mathrm{~g}$ were used for the study.

Cite This Article as: Ndeke AN, Mutembei HM, Kaingu CK and Muthee JK, 2021. Effect of acetaminophen on ovulation and implantation in female mice. International Journal of Veterinary Science 10(2): 141-143. https://doi.org/10.47278/journal.ijvs/2020.029 
The animals were purchased from the Kenya Medical Research Institute (KEMRI) and kept in cages within the laboratory. The mice were housed in groups of five and maintained under conditions of 12 hours light and 12 hours of darkness at room temperature. The mice accessed ad libitum commercially obtained diet of mice pellets (Unga Limited $($ ) and water. All the mice were subjected to an initial acclimatization period of two weeks before the start of the experiments.

Female Swiss white mice were randomly divided into two experiments, one testing effects on ovulation and the other testing effects on implantation. Each of the two groups was further sub-divided into treatment and control groups, each of them having $\mathrm{N}=5$ mice. Each of the mice in the treatment groups (TG1 and TG2) was given daily oral dosage of $200 \mathrm{mg} / \mathrm{kg}$ of acetaminophen (Panadol ${ }^{\circledR}$ GlaxoSmithKline) while those in the control groups (CG1 and $\mathrm{CG} 2$ ) received a daily oral dosage of the same quantities of normal saline placebo.

Experiment 1: Effect of Acetaminophen Ovulation: Mice received either Acetaminophen (TG1) or normal saline (CG1) daily via oral gavage for seven days before mating and continued until the $7^{\text {th }}$ day of pregnancy. The treatments were administered in the morning between 0700-0900 hours. On the seventh day of treatment, males of proven fertility were introduced into the cages at a ratio of 1:2. Vaginal fluid was taken daily thereafter and examined using a light microscope to determine the presence of spermatozoa. The day a vaginal plug was seen was considered day one of pregnancy. The mice were sacrificed on the seventh day of pregnancy and the uteri harvested to count the number of implantation sites.

Experiment 2: Effect of Acetaminophen on Implantation: Female mice were housed with males of proven fertility at a ratio of 1:2. Daily vaginal flushing was done using physiological saline to determine the presence of spermatozoa. The day a vaginal plug was seen was considered day one of pregnancy. Treatment was given via oral gavage daily between $0700-0900$ hours from $1^{\text {st }}$ to $7^{\text {th }}$ day of pregnancy. On the seventh day of pregnancy, the mice were sacrificed, and the uteri harvested to count the number of implantation sites.

Both experiments were repeated three times $(n=3)$. Data from all the mice in each experimental group was computed to obtain a group mean $(\mathrm{x} \pm \mathrm{SD})$ and the mean of all means of the repeated experiments computed to obtain the mean of the means $(m \pm S E M)$. Statistical difference between the mean of treatment and control group was tested using a student's t-test at a $95 \%$ confidence interval.

\section{RESULTS AND DISCUSSION}

All mice in both experiments mated successfully, and a vaginal plug was observed in all of them. There was a significant reduction of implantation sites in both treatment groups $(\mathrm{P} \leq 0.05)$ when compared with the respective control groups (Table 1).

Mice were used in this study because they have a short reproductive cycle and have been shown to have the highest level of anandamide in mammalian species (Schmid et al. 1997). Acetaminophen is a commonly used over the counter analgesic and this is why it was necessary to test its effect in this study. A significant reduction in the number of implantation sites $(\mathrm{P}<0.05)$ was observed in the treatment groups when compared to the control groups.

This result suggests a likely role of acetaminophen in the regulation of ovulation and implantation in female mice. Pre-coital administration of acetaminophen was utilized to create accumulated levels to check if it has any effects on the regulation of ovulation. On the other hand, the post-coital administration of acetaminophen was aimed at ensuring high levels are maintained to check for any effects on implantation. Therefore, an observation of a significant reduction of implantation sites in treated groups implies the effects of acetaminophen on either ovulation and/or implantation. Acetaminophen is an antiinflammatory drug that could be argued to affect ovulation by inhibiting prostaglandin (PGE) production as explained previously by Stone et al. (2002), who postulated that nonsteroidal anti-inflammatory drugs (NSAIDs) like acetaminophen inhibit ovulation leading to the formation of luteinized follicular cysts. Prostaglandins (PGs) produced within the preovulatory follicle are essential for ovulation to occur and administration of PG synthesis inhibitors has been shown to decrease follicular fluid PG levels and block ovulatory events in monkeys and women (Duffy et al. 2005). Besides this explanation, this finding could also be collaborating the evidence demonstrated by previous authors who through in-vitro studies postulated that acetaminophen activates the ECS to cause effects similar to those demonstrated for activated endocannabinoid system to inhibit ovulation and subsequently cause a reduction in the number of conceptus leading to reduced implantation sites (Bambang et al 2010; Cui et al. 2017; Maia et al. 2017; Ezechukwu et al. 2020; Maia et al. 2020).

The significant reduction in the number of implantation sites in mice treated with acetaminophen postcoitus can also be postulating a possible lone role of acetaminophen on implantation (Duffy et al. 2005). Being an anti-inflammation drug, it can be similarly be argued that acetaminophen will inhibit certain prostaglandins (PGE) that play vital roles in implantation by inhibiting cyclooxygenases 1 and 2 (COX-1 and COX-2), and prostaglandin E2 synthetases (cPGES, mPGES-1, and -2) at the site of implantation to prevent the paracrine crosstalk that facilitates feto-maternal communication leading to failure of nidation of the embryo (signalling, apposition, and attachment to the endometrium) (Salleh 2014). Acetaminophen has been demonstrated to undergo metabolic deacetylation in the liver to yield $p$-aminophenol (Mazaleuskaya et al. 2015) that undergo further conjugation with arachidonic acid via fatty acid amide hydrolase (FAAH) to result in the formation of $\mathrm{N}$ arachidonoyl-phenolamine (AM404) in the central nervous system (Sharma et al. 2017). Since AM404 has been shown to activate the ECS through selective binding to the cannabinoid receptor type 1 (CB1) to inhibit cellular uptake of anandamide and subsequently cause an increased buildup in levels of the same (anandamide) within the extracellular space to regulate implantation (Cui et al. 2017; Walker et al. 2019), the result, therefore, postulates a possible action of acetaminophen in inhibition of implantation leading to the observed reduction of implantation sites. 
Int J Vet Sci, 2021, 10(2): 141-143.

Table 1: Counted implantation sites of the experiment groups

\begin{tabular}{llccc}
\hline Parameters & \multicolumn{4}{c}{ Experiment groups } \\
\cline { 2 - 5 } & CG1 & TG1 & CG2 & TG2 \\
\hline Mean of Run 1 (x1 \pm SD) & $7.2 \pm 4.147$ & $5.0 \pm 4.64$ & $10 \pm 3.6$ & $1.6 \pm 3.57$ \\
Mean of Run 2 (x2 \pm SD) & $7.4 \pm 7.34$ & $4.2 \pm 5.848$ & $9.6 \pm 1.5$ & $1.8 \pm 4.02$ \\
Mean of Run 3 (x3 \pm SD) & $8.8 \pm 3.271$ & $1.8 \pm 4.025$ & $10.6 \pm 3.3$ & $3 \pm 4.12$ \\
Mean of Means (m \pm SEM) & $7.8 \pm 1.306$ & $3.67 \pm 1.306^{*}$ & $10.06 \pm 0.898$ & $2.13 \pm 0.898^{*}$ \\
\hline
\end{tabular}

*Statistically different from the corresponding control group $(\mathrm{P}<0.05) .(\mathrm{N}=5$ and $\mathrm{n}=3)$

The data from the experiments conducted demonstrate possible roles of acetaminophen in regulating ovulation and/or implantation either via anti-inflammatory effects and/or via the ECS route of action. Further elucidation is necessary, especially by histopathological examination of the ovary and the uterus of the treated mice to detect changes that may provide evidence on the most probable route of action for acetaminophen.

\section{Conclusion and Recommendations}

The evidence provided associates acetaminophen to anti-fertility effects probably by affecting ovulation and/or implantation in the mice. Two modes of actions are also postulated; either via the anti-inflammatory effect and/or the activation of ECS. Further studies are recommended to further elucidate the most probable mode of action by conducting histological examination of the ovaries and uteri of treated animals and/or molecular analysis of PGE systems. Once such studies are exhausted, a possibility of using acetaminophen as a possible anti-fertility contraceptive in animals and primates can be an option.

\section{Acknowledgement}

The authors are grateful to The Andys Veterinary Clinic for funding the research and everyone who in any way contributed to the success of the studies, including those who took care of the mice.

\section{REFERENCES}

Bambang KN, Karasu T, Gebeh A, Taylor AH, Marczylo TH, Lam $\mathrm{P}$ and Konje JC, 2010. From fertilisation to implantation in mammalian pregnancy-modulation of early human reproduction by the endocannabinoid system. Pharmaceuticals 39: 2910-2929. https://doi.org/10.3390/ ph3092910

Cecconi S, Rapino, Cinzia, DNV, Rossi G, and Maccarrone M, 2020. The endocannabinoid signaling in female reproduction: What are the latest advances? Progress in Lipid Research 77: https://doi.org/10.1016/j.plipres.2019. 101019.

Correa F, Wolfson ML, Valchi P, Aisemberg J and Franchi AM, 2016. Endocannabinoid system and pregnancy. Reproduction 152: R191-R200. https://doi.org/10.1530/ REP-16-0167.

Cui N, Wang L, Wang W, Zhang J, Xu Y, Jiang L, and Hao G. 2017. The correlation of anandamide with gonadotrophin and sex steroid hormones during the menstrual cycle The correlation of anandamide with gonadotrophin and sex steroid hormones during the menstrual cycle in Asian women. Iran Journal of Basic Medical Sciences 20: 1268-
1274. https://doi.org/10.22038/IJBMS.2017.9488.

Cui N, Wang C, Zhao Z, Zhang J, Xu Y, Yang Y and Hao G, 2017. The roles of anandamide, Fatty acid amide hydrolase, and leukemia inhibitory Factor on the endometrium during the implantation Window. Frontiers in Endocrinology 8: 268. https://doi.org/10.3389/fendo.2017.00268.

Duffy DM, Seachord CL and Dozer BL, 2005. Microsomal prostaglandin E synthase-1 ( mPGES-1 ) is the primary form of PGES expressed by the primate periovulatory follicle. Human Reproduction 20: 1485-1492. https://doi.org/ 10.1093/humrep/deh784.

Ezechukwu HC, Diya CA, Shrestha N and Hryciw DH, 2020. Role for endocannabinoids in early pregnancy: recent advances and the effects of cannabis use. American Journal of Physiology - Endocrinology and Metabolism 319: E557E561. https://doi.org/10.1152/AJPENDO.00210.2020

Maia J, Almada M, Silva A, Correia-da-Silva G, Teixeira N, Sá SI and Fonseca BM, 2017. The endocannabinoid system expression in the female reproductive tract is modulated by estrogen. Journal of Steroid Biochemistry and Molecular Biology 174: 40-47. https://doi.org/10.1016/j.jsbmb.2017. 07.023 .

Maia J, Fonseca B, Teixeira N and Correia-da-Silva G, 2020. The fundamental role of the endocannabinoid system in endometrium and placenta: implications in pathophysiological aspects of uterine and pregnancy disorders. Human Reproduction Update 264: 586-602. https://doi.org/10.1093/HUMUPD/DMAA005

Mazaleuskaya LL, Sangkuhl K, Thorn CF, Fitzgerald GA, Altman RB and Klein TE, 2015. PharmGKB summary: Pathways of acetaminophen metabolism at the therapeutic versus toxic doses. Pharmacogenetics and Genomics 258: 416-426. https://doi.org/10.1097/FPC.0000000000000150

Salleh N, 2014. Diverse roles of prostaglandins in blastocyst implantation. The Scientific World Journal 2014: Article ID 968141. https://doi.org/10.1155/2014/968141

Schmid PC, Paria BC, Krebsbach RJ, Schmid HHO and Dey SK, 1997. Changes in anandamide levels in mouse uterus are associated with uterine receptivity for embryo implantation Proceedings of the National Academy of Science 94: 41884192.

Sharma CV, Long JH, Shah S, Rahman J, Perrett D, Ayoub SS and Mehta V, 2017. First evidence of the conversion of paracetamol to AM404 in human cerebrospinal fluid. Journal of Pain Research 10: 2703-2709. https://doi.org/10.2147/ JPR.S143500.

Stone S, Khamashta, MA, Nelson-piercy, C and Reports C, 2002. Nonsteroidal anti-inflammatory drugs and reversible female infertility is there a link? Drug Safety 25: 545-551. https://doi.org/10.2165/00002018-200225080-00001.

Walker OLS, Holloway AC, and Raha S, 2019. The role of the endocannabinoid system in female reproductive tissues. Journal of Ovarian Research 121: 3. https://doi.org/10.1186/ s13048-018-0478-9. 